\title{
Subclavian Vein Thrombosis Revealing Hyperhomocysteinemia : Case Report And Review of Literature
}

Elfatemi B*, Bakkali T, Ouldaselek E, Tijani Y, El Khloufi S, Idrissi R, Sefiani Y, Lekehel B, Mesnaoui A, Ammar F, Bensaid Y

Vascular Surgery Service ibn Sina Hospital Rabat

DOI: $10.36347 /$ simcr.2020.v08i03.016

| Received: 03.03.2020 | Accepted: 10.03.2020 | Published: 13.03.2020

*Corresponding author: Elfatemi Bouthainah

Abstract

The association between hyperhomocysteinemia and venous thrombosis, which has been controversial for a long time, is now widely confirmed. The causes of hyperhomocysteinemia are multiple, both hereditary and acquired. The most common hereditary abnormality is the C677T mutation of methylenetetrahydrofolate reductase (MTHFR) in a heterozygote state. Hyperhomocysteinemia is a risk factor for venous thrombosis that should be investigated as part of the Thrombophilia assessment. The observation of a 21 year old patient with hyperhomocysteinemia diagnosed by a thrombosis of the subclavian vein will be reported first, then the role of this abnormality in the occurrence of arterial and venous thrombotic incidents will be recalled.

Keywords: Hyperhomocysteninemia- thrombosis risk factor- vein thrombosis-familial disease-thrombotic disease. Copyright @ 2020: This is an open-access article distributed under the terms of the Creative Commons Attribution license which permits unrestricted use, distribution, and reproduction in any medium for non-commercial use (NonCommercial, or CC-BY-NC) provided the original author and source are credited.

\section{INTRODUCTION}

The prevalence of hyperhomocysteinemia is estimated to be at about $5 \%$ in the global population. The causes of hyperhomocysteinemia are mainly genetic abnormalities, kidney disease, and a deficiency of folic acid, vitamin B6 or vitamin B12. Although the relationship between hyperhomocysteinemia and increased risk of thrombotic disease is widely confirmed for more than 30 years, sufficient data have only recently become available to suggest that this relationship is independent of other known risk factors and is concentration-dependent. An observation of this case is reported as a reminder of the role of hyperhomocysteinemia in the development of thrombotic disease.

\section{Observation}

This is a 21 year old patient with no pathologic medical history who consults for edema of the right upper limb, pain with collateral venous circulation and cyanosis. The examination found well-perceived distal pulses the rest of the clinical examination was unremarkable. A Doppler echo exam was performed which objectified a thrombosis of the subclavian vein. A phlebo-scan exam was performed confirming the thrombosis diagnosis. The patient had no clinical signs that could evoke a system disease, notably a Behçet disease, no notion of bi-polar aphtosis. An electromyogram exam was carried-out and was normal, thus ruling out thoracic brachial parade syndrome. Protein electrophoresis exam was normal. An inflammatory test was carried out showing a slightly increased sedimentation rate and normal $\mathrm{C}$-reactive protein. A Thrombophilia assessment was performed and the levels of protein $\mathrm{C}$, protein $\mathrm{S}$, anti beta2GP1, and antithrombin III were normal. The anti-LC antibody, circulating anticoagulant, and PLA were negative. Homocysteine was $15.78 \mathrm{micromol} / \mathrm{L}$. The patient was treated with anticoagulant (Sintrom): 1/2 tablet for the treatment of thrombosis. Homocysteine was controlled two months after is 14.40 micromol/l. Family screening was indicated in particular in the sister who was asymptomatic.

\section{Discussion}

Homocysteine is a sulphur amino acid intermediate of methionine metabolism, existing in plasma in free and protein-bound form. According to Ueland [1], approximately $70 \%$ of total plasma homocysteine is in the form of mixed disulfide bound to plasma proteins, particularly albumin. The remaining $20-30 \%$ of the so-called "free" material consists mainly of mixed disulphide and trace homocystine. As for the reduced Homocysteine, it is found only in a small percentage ( 2 to $3 \%$ ). The sum of all these forms 
constitutes total homocysteine. Its intracellular catabolism results from the action of vitamin-dependent enzymes which catalyze the two essentially hepatic pathways of equal quantitative importance: by the transsulphurisation pathway, homocysteine is first condensed with serine under the action of cystathionine b synthetase or CBS to give cystathionine. Cystathionine is then cleaved by cystathionase to form cysteine and acetobutyrate. Both of these enzymatic reactions have pyridoxal phosphate (vitamin B6) as a cofactor. This pathway is very important since cysteine is the source of glutathione, which is a major antioxidant sulphur amino acid. By the re-methylation pathway, homocysteine is so catalyzed to methionine by two parallel pathways: the first is under the action of the enzyme B12-dependent methionine synthetase. The methyl group is given by methyltetrahydrofolate reductase or MTHFR whose co-substrate is folate (vitamin B9).

There are many causes of hyperhomocysteinemia [2], the origin are both hereditary or acquired (deficiency in vitamins B6, B12, folic acid); the metabolism of homocysteine is also modified in certain physio-pathological situations (age, male sex, untreated menopause, tobacco, alcohol, renal failure...) or with certain drugs intakes (anticonvulsants, synthetic oestroprogestogens, isoniazid, theophylline, cyclosporine...).

Over the past 12 years, a large number of studies dealing with the relationship between homocysteine and stroke [3-6] have suggested that even small increases in homocysteine levels may be an independent risk factor for cardiovascular disease and thrombosis, as well as conventional risk factors. The prevalence of hyperhomocysteinemia in the global population is estimated to be about $5-10 \%$ (based on a threshold of $15 \mu \mathrm{mol} / \mathrm{l}$ ) and this rate increased to 30 $40 \%$ in the elderly.

One study reported that a high prevalence of hyperhomocysteinemia is observed in patients with a first episode of venous thrombosis compared to healthy subjects. The results showed that moderate hyperhomocysteinemia is independently associated with inaugural venous thrombosis and increases the risk of these diseases by more than 3 times. (7) Moderate hyperhomocysteinemia is then considered a risk factor for venous thromboembolism but its role in thrombogenic mechanisms is not yet understood. Although venous thromboembolism is responsible for half of the complications in homocystic patients [8], an association between moderate hyperhomocysteinemia and venous thrombosis has only been reported in the last decade. Several studies present moderate hyperhomocysteinemia as a risk factor for arterial thrombosis $[9,10,11,12]$ and venous thrombosis $[9,11,12]$. Another study showed that hyperhomocysteinemia is a prothrombotic factor that is very often observed in patients hospitalized for assessment of arterial thrombosis or venous thrombosis most often recurrent. This hyperhomocysteinemia can be easily treated by vitamin supplementation (folic acid, B vitamins). The long-term impact of reducing hyperhomocysteinemia on thrombotic recurrence remains to be investigated.

The studies reported in the literature indicates that moderate hyperhomocysteinemia is found with a frequency of $19-47 \%$ in arterial thrombosis $[13,14,12$ $16]$ and $10-25 \%$ in venous thrombosis $[11,15,17-21]$. A meta-analysis [109] of nine case-control studies published between 1991 and 1997 confirmed the hypothesis that moderate hyperhomocysteinemia increases the risk of venous thromboembolism. Moderate hyperhomocysteinemia is usually related to the simultaneous presence of an insufficient folic diet and a so-called heat-labile MTHFR (by mutation C $>$ T in position 677) [22]. This is a very common case as this mutation is present in a homozygous state in about $10 \%$ of the population [8]. It occurs in half the cases before the age of 30 . About $30-50 \%$ of cystathionine bsynthase deficiencies can be treated with vitamin B6 supplementation (coenzyme of the enzyme). These patients, in whom "traces" of cystathionine b-synthase usually persist, will normalize their plasma homocysteine levels. The prognosis for cystathionine bsynthase deficiency has been revolutionized by this treatment and the mortality rate (in susceptible subjects) has been reduced from $20 \%$ (at 30 years of age) to less than 5\% [23]. In patients resistant to vitamin B6 and, depending on the type of enzyme deficiency, different treatments may combine vitamins B12 and B9 as well as high doses of betaine (MTHFR deficiency). However, some deficiencies are resistant to all these treatments (particularly in the case of a total absence of cystathionine b-synthase) and a strict hypoprotidic diet low in methionine is then necessary. Given the simplicity and the great potential efficacy of the treatment of this rare pathology, we feel it is important not to omit homocysteinemia testing in patients, especially young subjects, who have had venous or arterial thrombosis. Many risk factors for thrombotic disease have been studied in thrombosis assessments. Quantitative or qualitative abnormalities in physiological inhibitors may explain maximum $15 \%$ of cases of familial thrombophilia; the identification of prothrombotic mutations in coagulation factors (factor $\mathrm{V}$ gene mutation, factor II gene mutation) has led to an advance in the interpretation of thrombotic pathology, particularly venous thrombophilia. Among the acquired biological risk factors, the presence of lupus anticoagulant has also led to the interpretation of a number of thromboses. Recently, the role of Hcys in thrombotic pathology has often been cited to explain cases of unconventional thrombosis [24,25,26]. One study showed significantly higher rates in patients under 60 years of age with venous or arterial thrombosis compared to controls, a difference that was 
especially marked in women between $30-44$ years old. There is also a significant difference between the pathologies. This study also revealed that on average non-smoking and/or non-hypercholesterolemic patients have higher homocysteine (Hcys) levels than patients with these risk factors (although smoking has been shown to increase circulating Hcys), demonstrating the independent role of Hcys in the development of thrombosis [27,25]. Finally, the Hcys level appears to be linked with many coagulation factors such as TA, SP and free SP. It therefore appears that Hcys is indeed an independent risk factor for thrombosis, and is thought to ensure a predominant role in stroke compared to the other pathologies compared. Routine dosing should be performed in all patients with a family history of early thrombotic disease in order if it is required to initiate a vitamin therapy in case of deficiency.

\section{Conclusion}

Hyperhomocysteinemia is a risk factor that has been confirmed in the genesis of inaugural or recurrent arterial and venous thrombosis and is independent of other thrombotic risk factors. Its research should be a systematic part of the thrombophilia test. Its treatment involves a folic acid supplementation.

\section{REFERENCE}

1. Ueland PM, Refsum H, Stabler SP, Malinow MR, Andersson A, Allen RH. Total homocysteinemia in plasma or serum: methods and clinical applications. Clin Chem. 1993 ;39(9): 1764-79.

2. Eichinger S, Stümpflen M. Hyperhomocysteinemia is a risk factor of recurrent venous thromboembolism. Thromb Haemost. $1998 ; 80$ :566-9.

3. Boushey CJ, Beresford SA, Omenn GS, MotulskyAG.A quantitative assessment of plasma homocysteine as a risk factor for vascular disease. Probable benefits of increasing folic acid intakes. JAMA. 1995 ;274(13) :1049-57.

4. Carson NA, Neill DW. Metabolic abnormalities detected in a survey of mentally backward individuals in Northern Ireland. Arch Dis Child. $1962 ; 37: 505-13$.

5. Gibelin $\mathrm{P}$, Candito $\mathrm{M}$, Houenassi $\mathrm{M}$, Van Obberghen E, Morand P, Baudouy M. Homocystéine et insuffisance coronarienne aiguë. Presse Med. 1997 ;26(30) :1425-8.

6. Marcucci R, Brunelli T, Giusti B, Fedi S, Pepe G, Poli D.The role of cysteine and homocysteine in venous and arterial thrombotic disease. Am J Clin Pathol. 2001 ;116(1) :56-60.

7. Semraa K, Benmebareka K, Boukhalkhal A. Roula $\mathrm{D}$, Benlatreche C. Variation de l'homocystéinémie au cours des thromboses veineuses inaugurales. Jmv. 2013. $1016: 12-055$

8. Rees MM, Rodgers GM. Homocysteinemia: Association of a metabolic disorder with vascular disease and thrombosis. Thromb Res. 1993; 71
:337-9.

9. Clarke R, Daly L, Robinson K, Naughten E, Cahalane S, Fowler B. Hyperhomocysteinemia: an independent risk factor for vascular disease. N Engl J Med. $1991 ; 324: 1149-55$.

10. Boers GHJ, Smals AGH, Trijbels FJM, Fowler B, Bakkeren JAJM, Schoonderwalt HC. Heterozygosity for homocystinuria in premature peripheral and cerebral occlusive arterial disease. $\mathrm{N}$ Engl J Med. $1985 ; 313$ :709 15.

11. Mudd SH. Vascular disease and homocysteine metabolism. N Engl J Med. 1985 ;313 :751-3.

12. Bienvenu T, Ankri A, Chadefaux B, Montalescot G, Kamoun P. Elevated total plasma homocysteine, a risk factor for thrombosis. Relation to coagulation and fibrinolytic parameters. Throm Res $1993 ; 70$ :123-9.

13. Molgaard J, Malinow MR, Lassvik C, Holm A- C, Upson B. Olsson AG Hyperhomocyst(e)inemia: an independent risk factor for intermittent claudication. J Intern Med. 1992 ;231 :273-9.

14. Bergmark C, Mansoor MA, Swedenborg J, de Faire U, Svardal AM. Ueland PM Hyperhomocysteinemia in patients operated for lower extremity ischemia below the age 50 : effect of smoking and extent of disease. Eur J Vasc Surg $1993 ; 7: 391-7$.

15. Fermo I, Vignano d'Angelo S, Paroni R, Mazzola G, Calori G, d'Angelo A. Prevalence of moderate hyperhomocysteinemia in patients with early-onset venous and arterial occlusive disease. Ann Intern Med. 1995;123:747-53.

16. Malinow MR, Kang SS, Taylor LM, Wong PW, Coull B, Inahara T, Mukerjee D. Prevalence of hyperhomocyst(e)inemia in patients with peripheral arterial occlusive disease. Circulation. $1989 ; 79$ : 1180-8.

17. den Heijer M, Koster T, Blom HJ, Bos GMJ, Briët E, Reitsma PH. Hyperhomocysteinemia as a risk factor for deepvein thrombosis. N Engl J Med. $1996 ; 334: 759-62$.

18. Falcon CR, Cattaneo M, Panzeri D, Martinelli I, Mannucci PM. High prevalence of hyperhomocyst(e)inemia in patients with juvenile venous thrombosis. Arterioscler Thromb. $1994 ; 14$ :1080-3.

19. Admundsen T, Ueland PM. Waage A Plasma homocysteine levels in patients with deep veinous thrombosis. Arterioscler ThrombVasc Biol. 1995; $15: 1321-3$.

20. Simioni P, Prandoni P, Burlina A, Tarmene D, Sardella C, FerrariV. Hyperhomocysteinemia and deep-vein thrombosis. Thromb Haemost. 1996 ;76 :883-6.

21. Den Heijer M, Blom HJ, Gerrits WBJ, Rosendaal FR, Haak HL, Wijermans PW. Is hyperhomocysteinemia a risk factor for recurrent venous thrombosis ? Lancet. $1995 ; 345: 882-5$.

22. Den Heijer M, Rosendaal FR, Blom HJ, Gerrits WB, Bos GM. Hyperhomocysteinemia and venous 
thrombosis : A meta-analysis. Thromb Haemost. $1998 ; 80: 874-7$.

23. Kang SS, Zhou J, Wong PWK, Kowalisyn J, Strokosch G. Intermediate homocysteinemia : a thermolabile variant of methylenetetrahydrofolate reductase. Am J Hum Genet. 1988 ;43 :414-21.

24. Mudd HS, Skovby F, Levy HL, Pettigrew KD, Wilcken B, Pyeritz RE. The natural history of homocystinuria due to cystathionine b-synthase deficiency. Am Hum Genet. 1985;37: 1-31.

25. Perry IJ, Refsum H, Morris RW, Ebrahim SB, Ueland PM, ShaperAG. Prospective study of serum total homocysteine concentration and risk of stroke in middle-aged british men. Lancet. 1995; 346(8987):1395-8.

26. Refsum H, Ueland PM, Nygard O, Vollset SE. Homocysteine and cardiovascular disease. Ann Rev Med $1998 ; 49: 31-62$.

27. Nygard O, Vollset SE, Refsum H, Stensvold I, Tverdal A, Nordrehaug JE. Total plasma homocysteine and cardiovascular risk profile. The Hordaland Homocysteine study. JAMA. 1995; 274(19): 1526-33. 